\title{
Prevalence of neck pain in subjects with metabolic syndrome - a cross-sectional population-based study
}

\author{
Pekka Mäntyselkä ${ }^{*}$, Hannu Kautiainen², Mauno Vanhala ${ }^{3}$
}

\begin{abstract}
Background: Metabolic syndrome (MetS) is increasingly common. Obesity has been suggested to associate with neck pain but prevalence of neck pain in subjects with MetS has not been studied. Aim of this study was to analyse the association between MetS and neck pain.

Methods: The study population consisted of 1294 middle-aged subjects in Pieksämäki, Finland. A total of 399 males and 500 females participated (69\%). The mean age of both males and females was 46 years. Clinical and biochemical measurements were taken. The participants filled out a standard questionnaire. Psychological distress was assessed with the 12-item General Health Questionnaire (GHQ-12). Neck pain was defined as neck pain perceived daily. MetS was defined using National Cholesterol Education Program (NCEP) criteria. Statistical comparisons between the groups were performed using a bootstrap-type t-test or Chi-Square test. Risk ratios of having neck pain were calculated using generalised linear models with age, smoking, alcohol use, exercise and GHQ-12 score as covariates.
\end{abstract}

Results: The prevalence of MetS was 33\% in males and 29\% in females. Neck pain was present in 11\% ( $N=42)$ of males and 19\% ( $\mathrm{N}=93)$ of females ( $\mathrm{P}<0.001)$. The prevalence of neck pain was $7.9 \%(95 \% \mathrm{Cl}, 4.9 \%$ to $12 \%)$ among male subjects without MetS and $16 \%(95 \% \mathrm{Cl}, 10 \%$ to $23 \%)$ among those with MetS. The respective proportions among females were $16 \%(95 \% \mathrm{Cl}, 12 \%$ to $20 \%)$ and $25 \%(95 \% \mathrm{Cl}, 18 \%$ to $33 \%)$. The multivariate analysis showed an increased risk of neck pain in males with MetS (RR $2.1,95 \% \mathrm{Cl}, 1.2$ to $3.7, \mathrm{P}=0.010$ ) and in females with MetS (RR 1.5, 95\% Cl, 1.0 to $2.1, \mathrm{P}=0.040$ ).

Conclusions: MetS was associated with neck pain. This association was stronger in males, but the prevalence of neck pain was higher in females. Prospective studies should explore the potential causal association between neck pain and MetS and the potential common background factors of neck pain and MetS.

\section{Background}

Metabolic syndrome (MetS) has become increasingly common worldwide [1]. Metabolic syndrome (MetS) is a cluster of risk factors defined by high fasting glucose and triglycerides, low HDL cholesterol, high blood pressure, and abdominal obesity that increases the risk for cardiovascular diseases, type 2 diabetes mellitus, and allcause mortality [2-4]. The prevalence of MetS in the US population is approximately 35\% [5]. In Eastern Finland the corresponding prevalence has been found to be $37 \%$

\footnotetext{
* Correspondence: pekka.mantyselka@uef.fi

'School of Medicine, Primary Health Care, University of Eastern Finland, Kuopio, Finland and Unit of Primary Health Care, Kuopio University Hospital, Kuopio, Finland
}

(c) 2010 Mäntyselkä et al; licensee BioMed Central Ltd. This is an Open Access article distributed under the terms of the Creative Commons Attribution License (http://creativecommons.org/licenses/by/2.0), which permits unrestricted use, distribution, and reproduction in any medium, provided the original work is properly cited.
[6]. Neck pain is also a common symptom among the middle-aged population. In a large Finnish populationbased study, $24 \%$ of men and $37 \%$ of women aged at least 30 years had suffered from neck pain during the preceding month [7].

There are few studies in which the prevalence of pain has been assessed in subjects with MetS. In one study females with chronic pain from fibromyalgia were at an increased risk of MetS [8]. Another study found that subjects with metabolic syndrome were more likely to have problems with pain symptoms [9]. It has been suggested that stress is related to both MetS and neck pain $[10,11]$. Low physical activity has been found to be associated with MetS [12] and musculoskeletal pain [13]. 
Some studies have found an association between obesity and neck pain $[14,15]$. Because visceral obesity is one of the main features of MetS, it could be proposed that MetS is also related to neck pain. It has been speculated that both MetS and persistent chronic pain syndromes are related to hypothalamus-pituitary-adrenal stress axis dysfunction [16,17]. Therefore, it could be expected that the prevalence of neck pain is elevated in subjects with MetS. Thus, if there were common features in the background of these disorders, we hypothesized that neck pain is more prevalent among subjects with MetS than among those without MetS. In this study we aimed to analyse the prevalence of neck pain in subjects with MetS.

\section{Methods}

The original study population consisted of middle-aged, Finnish subjects $(\mathrm{N}=1294)$ born in $1942,1947,1952$, 1957 and 1962 (the entire age groups, age range at the baseline being 35-56 years) in Pieksämäki, a town in eastern Finland. Altogether 923 of 1294 subjects (71.3\%) participated in the initial examination in 1997-98. The mean age of the study population was 46 years. Body mass index was $26.7 \mathrm{~kg} / \mathrm{m}^{2}$ in men and $26.3 \mathrm{~kg} / \mathrm{m}^{2}$ in women $(\mathrm{P}=0.15)$ [18]. For the present study, complete data were available for 399 males and 500 females who participated. The mean age of both males and females was 46 years. The prevalence of neck pain was analysed stratified by sex because prevalence of MetS in Finland is more prevalent among males than females $[5,18]$. Further, neck pain is more common among females than among males [7] and the factors associating with neck pain may be different in females [19].

Metabolic syndrome was defined based on the criteria proposed by the NCEP [20]. In the evaluation of MetS, we used the modified National Cholesterol Education Program - Adult Treatment Panel III criteria (NCEPATP III), with the $5.6 \mathrm{mmol} / \mathrm{l}$ blood glucose cut-off point [21]. NCEP defines MetS as having three or more of the following criteria: 1) fasting serum glucose of $5.6 \mathrm{mmol} / \mathrm{l}$ or higher, 2) serum triglycerides of $1.7 \mathrm{mmol} / \mathrm{l}$ or higher, 3) serum high-density lipoprotein (HDL) cholesterol $<1.03 \mathrm{mmol} / \mathrm{l}$ in men or $<1.29$ $\mathrm{mmol} / \mathrm{l}$ in women, 4) blood pressure of $130 / 85 \mathrm{mmHg}$ or higher and 5) waist circumference $>102 \mathrm{~cm}$ in men or $>88 \mathrm{~cm}$ in women. Serum triglycerides, cholesterol, high-density lipoprotein (HDL) cholesterol, glucose and high sensitivity C-reactive protein (hs-CRP) were measured [18]. Blood pressure was measured twice at $5 \mathrm{~min}$ intervals; the readings from the second measurement were used in the analyses. Body mass index (BMI) was calculated as $\mathrm{kg} / \mathrm{m}^{2}$. Persons who smoked at least once a week were labelled as current smokers. Current use of alcohol was defined as alcohol consumption at least once a year. Leisure time physical activity was defined as physical exercise that lasted at least 30 minutes per session and caused sweating. There were three categories of physical exercise: low activity (1-2 times a month or less), moderate activity (1-3 times a week) and high activity (more than 3 times a week).

Psychological distress was assessed with the 12-item General Health Questionnaire (GHQ-12) [22]. The fourpoint response scale was rated as follows: presence of symptom: not at all $=0$, same as usual $=0$, more than usual $=1$, much more than usual $=1$. The study subjects were allocated into three groups according to their scores (0 points, 1-2 points and 3-12 points).

Neck pain was assessed by asking about neck pain during the preceding month. The presence of neck pain was dichotomized: (0) no neck pain or neck pain only occasionally and (1) daily or almost daily neck pain. Hence, in this study we regarded neck pain as daily or almost daily occurring neck pain.

Statistical comparisons between the groups were performed using a bootstrap-type t-test or Chi-Square test. Risk ratios (RR) of having neck pain were estimated by a generalised linear model with the binomial family, log link, and robust standard error. In these analyses age, smoking, alcohol use, exercise and GHQ-12 score were used as covariables in order to control for factors that potentially influence the relationship between neck pain and MetS. It has been found that smoking can affect the impact of neck pain, but moderate alcohol use may have a protective effect [23]. Low physical activity has been found to be associated with MetS and musculoskeletal pain $[12,13]$. Psychological distress has been suggested to be related to both MetS [24] and neck pain [19]. Confidence intervals (CI) for the percentages were obtained by exact (Clopper-Pearson) methods. Stata statistical software, release 10 (StataCorp, College Station, Texas) was used for the analyses.

This study was approved by the Ethics Committee of the Kuopio University Hospital. All the participants gave an informed consent.

\section{Results}

The mean age of the male study subjects was 46.1 years (SD 6.3 years) and that of the females was 45.9 years (SD 6.2 years) $(\mathrm{P}=0.69)$. MetS was present in 132 men (33\%) and 146 women (29\%). Neck pain was present in $18.6 \%(\mathrm{~N}=93)$ of the females and $10.5 \%(\mathrm{~N}=42)$ of the males $(\mathrm{P}<0.001)$. The subjects with neck pain were slightly but not significantly older than those who had no neck pain. The mean age of the male subjects without neck pain was 46.0 (SD 6.3) years and that of the subjects with neck pain was 47.0 years (SD 6.3) $(\mathrm{P}=$ $0.30)$. The corresponding mean ages of the females were 45.6 years $(\mathrm{SD} 6.2)$ and 47.0 years $(\mathrm{SD} 6.2)(\mathrm{P}=0.06)$. 
Table 1 Clinical data in males and females according to neck pain status

\begin{tabular}{|c|c|c|c|c|c|c|}
\hline & \multicolumn{3}{|c|}{ MALES $(\mathrm{N}=399)$} & \multicolumn{3}{|c|}{ FEMALES $(\mathrm{N}=500)$} \\
\hline & $\begin{array}{l}\text { No Neck Pain } \\
(\mathrm{N}=357)\end{array}$ & $\begin{array}{l}\text { Neck Pain } \\
(\mathrm{N}=42)\end{array}$ & P-value & $\begin{array}{l}\text { No Neck Pain } \\
(\mathrm{N}=407)\end{array}$ & $\begin{array}{l}\text { Neck Pain } \\
(\mathrm{N}=93)\end{array}$ & P-value \\
\hline Metabolic syndrome, N (\%) & $111(31)$ & $21(50)$ & 0.014 & $110(27)$ & $36(39)$ & 0.025 \\
\hline Diabetes, N (\%) & $30(8.4)$ & $2(4.8)$ & 0.41 & $23(5.7)$ & $3(3.2)$ & 0.34 \\
\hline Antihypertensive medication, N (\%) & $33(9)$ & $8(19)$ & 0.048 & $29(7)$ & $14(15)$ & 0.014 \\
\hline Lipid-lowering medication, N (\%) & $11(3.1)$ & $1(2.4)$ & 0.80 & $5(1.2)$ & $1(1.1)$ & 0.90 \\
\hline Smoking, N (\%) & $121(34)$ & $15(36)$ & 0.81 & $87(21)$ & $25(27)$ & 0.25 \\
\hline Alcohol use, N (\%) & $312(87)$ & $35(83)$ & 0.46 & $332(82)$ & $67(72)$ & 0.039 \\
\hline Physical activity* high, N (\%) & $49(14)$ & $5(12)$ & 0.94 & $59(14)$ & $11(12)$ & 0.85 \\
\hline Diastolic blood pressure, mmHg, mean (SD) & $83.5(9.9)$ & $85.3(11)$ & 0.30 & $79.7(9.3)$ & $79.5(10)$ & 0.85 \\
\hline Systolic blood pressure, mean, mmHg (SD) & $136.1(17)$ & $141.0(19)$ & 0.12 & $131.2(17)$ & $131.3(19)$ & 0.94 \\
\hline Body Mass Index, $\mathrm{kg} / \mathrm{m}^{2}$, mean (SD), & $26.5(3.4)$ & $28.0(5.5)$ & 0.012 & $26.4(5.4)$ & $26.6(4.6)$ & 0.74 \\
\hline Waist circumference, $\mathrm{cm}$, mean (SD) & $93(10)$ & $98(14)$ & 0.0081 & $83(12)$ & $85(13)$ & 0.19 \\
\hline S-cholesterol $^{\dagger}, \mathrm{mmol} / \mathrm{l}$, mean (SD) & $5.8(1.0)$ & $6.1(1.3)$ & 0.20 & $5.6(0.9)$ & $5.8(1.2)$ & 0.26 \\
\hline S-HDL-cholesterol ${ }^{\#}$, mmol/l, mean (SD) & $1.3(0.3)$ & $1.3(0.3)$ & 0.86 & $1.5(0.3)$ & $1.5(0.3)$ & 0.57 \\
\hline S-triglyserides, mmol// mean (SD) & $1.6(1.0)$ & $2.2(2.5)$ & 0.16 & $1.2(0.6)$ & $1.3(0.7)$ & 0.11 \\
\hline P-glucose ${ }^{\ddagger}, \mathrm{mmol} /$, mean (SD) & $6.0(0.9)$ & $5.9(0.6)$ & 0.54 & $5.6(0.6)$ & $5.7(0.5)$ & 0.75 \\
\hline hs-CRP", mg/l, mean (SD) & $1.5(2.8)$ & $1.8(1.8)$ & 0.41 & $1.7(2.3)$ & $1.8(1.7)$ & 0.65 \\
\hline GHQ-12 $2^{\S}$ sum, mean (SD) & $1.3(2.4)$ & $2.5(3.1)$ & 0.002 & $1.5(2.7)$ & $3.6(3.9)$ & $<0.001$ \\
\hline
\end{tabular}

* Leisure time physical activity was defined as physical exercise that lasted at least 30 minutes per session and caused sweating. There were three categories: low activity (1-2 times a month or less), moderate activity (1-3 times a week) and high activity (more than 3 times a week).

†S-cholestero I = Serum cholesterol.

\# S-HDL-cholesterol = Serum high density lipoprotein cholesterol.

₹ P-glucose = Plasma glucose.

I hs-CRP $=$ High sensitivity C-reactive protein.

$\S \mathrm{GHQ}-12=12$-item General Health Questionnaire.

The clinical data are presented in Table 1. Compared with the subjects who had no neck pain, MetS was more prevalent among males and females who suffered from neck pain. The subjects with neck pain more often had antihypertensive medication than did those without neck pain. Alcohol use was inversely related to neck pain in females but not in males. BMI and waist circumference were associated with neck pain in males but not in females. The GHQ-12 score was significantly higher for males and females with neck pain than for those who had no neck pain. There were no significant differences in smoking, physical activity, blood pressure, lipids, glucose and CRP levels between the subjects with neck pain and without neck pain.

Compared with the subjects without metabolic syndrome, both male and female subjects with metabolic syndrome more often had neck pain (Figure 1 and Table 1). The prevalence of neck pain was $7.9 \%$ (95\% CI, $4.9 \%$ to $12 \%$ ) among male subjects without MetS and $16 \%(95 \% \mathrm{CI}, 10 \%$ to $23 \%, \mathrm{P}=0.014)$ among those with MetS. The respective proportions were 16\% (95\% CI, $12 \%$ to $20 \%$ ) and $25 \%$ (95\% CI, $18 \%$ to $33 \%, \mathrm{P}=$ $0.025)$ among females.

In the univariate analysis MetS was associated with neck pain (a crude risk for males and females, $\mathrm{RR}=1.6$ (95\% CI, 1.2 to 2.2 )). The risk ratio was 2.0 (95\% CI, 1.1 to $3.6, \mathrm{P}=0.015)$ in males and $1.5(95 \% \mathrm{CI}, 1.1$ to $2.2, \mathrm{P}$ $=0.024)$ in females. The multivariate analysis (Table 2) showed an increased risk of neck pain for male subjects with MetS (RR 2.1, 95\% CI, 1.2 to 3.7, P = 0.010). Also the GHQ score indicated an increased risk of neck pain in males. The RR of a GHQ score of 3 or more was 3.2 (95\% CI, 1.7 to 6.1). Female subjects with MetS had a risk of neck pain (RR 1.5, 95\%, 1.0 to $2.1, \mathrm{P}=0.040$ ). In females a GHQ score was associated with neck pain. The risk ratio of a GHQ score of 1 to 2 was 2.7 (95\% CI, 1.7 to $4.4, \mathrm{P}<0.001$ ), and for a GHQ score of 3 or more the RR was 3.0 (95\% CI, 1.9 to $4.6, \mathrm{P}<0.001$ ). Age, smoking, alcohol use and physical activity were associated with neck pain in neither males nor females.

\section{Discussion}

This study showed that males and females with metabolic syndrome have an increased prevalence of neck pain. This association was stronger in males, but the prevalence of neck pain was higher in females. In accordance with previous studies, psychological distress was associated with neck pain especially in females. Although psychological distress was taken into account, MetS was statistically associated with neck pain.

BMI was higher and waist circumference larger in males with neck pain. Previous studies have suggested 


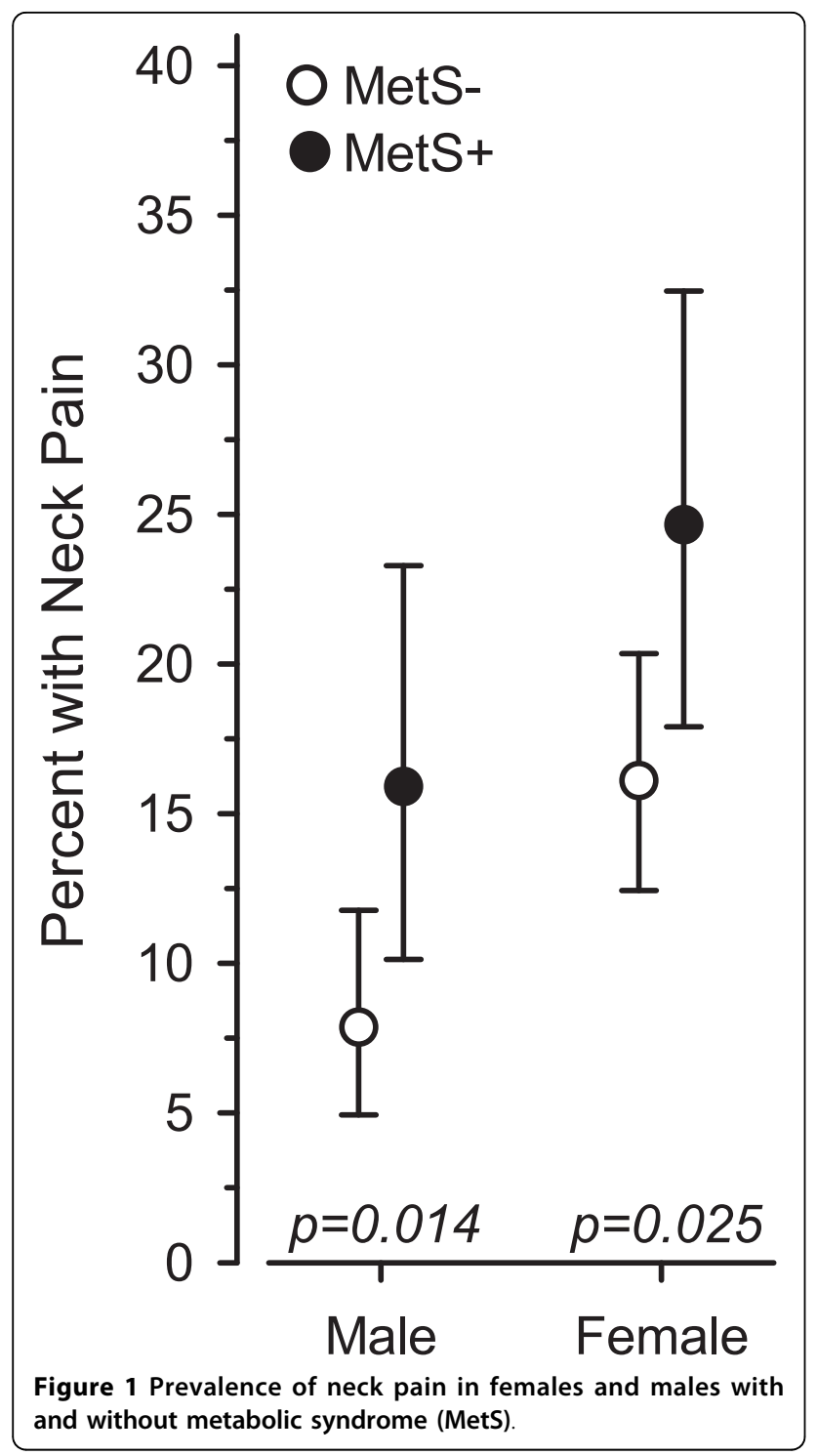

that obesity is a risk factor of neck pain $[14,15]$. Subjects with MetS are often obese and waist size is among the criteria of MetS. However, BMI and waist size were similar in females regardless of neck pain. Therefore, it is not plausible that the association between MetS and neck pain is related solely to obesity. Compared with females, males with neck pain had higher cholesterol and triglyceride levels and a higher BMI. Psychological distress was associated with neck pain in both genders. However, a lower lever of distress was associated with neck pain in females, but in males only severe distress had that association. In general, the level of psychological distress was higher among females than among males. According to a large population-based study, concurrent psychological distress is more prevalent among females [19].

The population of the present study was from a limited area in Finland, and the number of subjects with neck pain was not very large. Therefore, our results should be regarded as preliminary and they should be generalized cautiously to other populations. The assessment of neck pain was based on self-reports and we did not more deeply assess the diagnostic features of these symptoms, which also is a potential limitation of our study.

One background hypothesis for the connection between neck pain and MetS found in this study is that there is a common factor resulting in the development of both neck pain and MetS. Two such factors could be stress and physical inactivity. Stress has been suggested to be a risk factor of MetS [10]. A recent study has suggested that workers with neck, shoulder, or back pain have elevated levels of stress-related biomarkers [11]. Further, it can be speculated that neck pain is an indicator of stress. A recent study has shown that in a specified population, physical inactivity is a risk of MetS, whereas perceived stress was not associated with MetS

Table 2 Risk ratios of neck pain in males and females

\begin{tabular}{|c|c|c|c|c|}
\hline & \multicolumn{2}{|c|}{ MALES } & \multicolumn{2}{|c|}{ FEMALES } \\
\hline & $\begin{array}{c}\text { Risk Ratio } \\
(95 \% \mathrm{Cl})\end{array}$ & P-Value & $\begin{array}{c}\text { Risk Ratio } \\
(95 \% \mathrm{Cl})\end{array}$ & P-Value \\
\hline Metabolic syndrome & $2.09(1.19-3.67)$ & 0.01 & $1.46(1.02-2.10)$ & 0.04 \\
\hline Age & $1.00(0.96-1.05)$ & 0.89 & $1.02(0.99-1.05)$ & 0.25 \\
\hline \multicolumn{5}{|l|}{ Physical Activity* } \\
\hline Moderate & $0.89(0.47-1.66)$ & 0.70 & $0.97(0.66-1.44)$ & 0.89 \\
\hline High & $0.73(0.29-1.87)$ & 0.53 & $0.70(0.38-1.29)$ & 0.25 \\
\hline \multicolumn{5}{|l|}{ Psychologic distress } \\
\hline Moderate (GHQ-12 ; 1-2) & $1.64(0.77-3.49)$ & 0.20 & $2.74(1.69-4.45)$ & $<0.001$ \\
\hline High (GHQ-12; 3-12) & $3.201 .67-6.13)$ & $<0.001$ & $2.98(1.91-4.64)$ & $<0.001$ \\
\hline Smoking & $1.02(0.57-1.83)$ & 0.94 & $1.32(0.90-1.93)$ & 0.16 \\
\hline Alcohol use & $0.75(0.36-1.56)$ & 0.44 & $0.73(0.50-1.07)$ & 0.11 \\
\hline
\end{tabular}

Results of multivariate analysis.

* Leisure time physical activity was defined as physical exercise that lasted at least 30 minutes per session and caused sweating. There were three categories: low activity (1-2 times a month or less), moderate activity (1-3 times a week) and high activity (more than 3 times a week).

$\S \mathrm{GHQ}-12=12$-item General Health Questionnaire. 
[25]. The association between development of MetS and low physical inactivity has also been shown in a previous study [12]. A large epidemiological follow-up study indicated that physical inactivity is related to chronic musculoskeletal complaints [13]. It has been suggested that chronic musculoskeletal pain is associated with cardiovascular-related mortality [26]. Hence, physical inactivity may be an intervening factor between MetS and neck pain. Further studies with a longitudinal setting could explore the potential causal association between neck pain and MetS as well as the potential common background factors of neck pain and MetS.

\section{Conclusions}

MetS was associated with neck pain. This association was stronger in males but the prevalence of neck pain was higher in females. Prospective studies focusing on the causal relationship between neck pain and metabolic syndrome are needed.

\section{Acknowledgements}

This study has been supported by the Northern Savo and Central Finland Hospital Districts.

\begin{abstract}
Author details
${ }^{1}$ School of Medicine, Primary Health Care, University of Eastern Finland, Kuopio, Finland and Unit of Primary Health Care, Kuopio University Hospital, Kuopio, Finland. ${ }^{2}$ ORTON Foundation, Helsinki, Finland. ${ }^{3}$ School of Medicine, Primary Health Care, University of Eastern Finland, Kuopio, Finland and Unit of Family Practice, Central Hospital of Middle Finland, Jyväskylä, Finland.
\end{abstract}

\section{Authors' contributions}

PM participated in the analysis of data and in design of the manuscript and drafted the manuscript. HK analysed the data and participated in design of the manuscript. MV conceived of the study and participated in its design, analysis and coordination and helped to draft the manuscript. All authors read and approved the final manuscript.

\section{Competing interests}

The authors declare that they have no competing interests.

Received: 21 September 2009 Accepted: 30 July 2010

Published: 30 July 2010

\section{References}

1. Grundy SM: Metabolic syndrome pandemic. Arterioscler Thromb Vasc Biol 2008, 28:629-636.

2. Expert Panel on Detection, Evaluation, and Treatment of High Blood Cholesterol in Adults: Executive Summary of The Third Report of The National Cholesterol Education Program (NCEP) Expert Panel on Detection, Evaluation, And Treatment of High Blood Cholesterol In Adults (Adult Treatment Panel III). JAMA 2001, 285:2486-2497.

3. Lakka HM, Laaksonen DE, Lakka TA, Niskanen LK, Kumpusalo E, Tuomilehto J, Salonen JT: The metabolic syndrome and total and cardiovascular disease mortality in middle-aged men. JAMA 2002, 288:2709-2716.

4. Ford ES: Risks for all-cause mortality, cardiovascular disease, and diabetes associated with the metabolic syndrome: a summary of the evidence. Diabetes Care 2005, 28:1769-1778.

5. Ford ES: Prevalence of the metabolic syndrome defined by the International Diabetes Federation among adults in the U.S. Diabetes Care 2005, 28:2745-2749.
6. Miettola J, Niskanen LK, Viinamaki H, Kumpusalo E: Metabolic syndrome is associated with self-perceived depression. Scand J Prim Health Care 2008, 26:203-210.

7. Kaila-Kangas L, editor: Musculoskeletal disorders and diseases in Finland. Results of the Health 2000 Survey. Helsinki: Publications of the National Public Health Institute B25/2007 2007.

8. Loevinger BL, Muller D, Alonso C, Coe CL: Metabolic syndrome in women with chronic pain. Metabolism 2007, 56:87-93.

9. Han JH, Park HS, Shin $\mathrm{Cl}$, Chang HM, Yun KE, Cho SH, Choi EY, Lee SY, Kim JH, Sung HN, Kim JH, Choi SI, Yoon YS, Lee ES, Song HR, Bae SC: Metabolic syndrome and quality of life (QOL) using generalised and obesity-specific QOL scales. Int J Clin Pract 2009, 63:735-741.

10. Chandola T, Brunner E, Marmot M: Chronic stress at work and the metabolic syndrome: prospective study. BMJ 2006, 4(332):521-525.

11. Schell E, Theorell T, Hasson D, Arnetz B, Saraste H: Stress biomarkers' associations to pain in the neck, shoulder and back in healthy media workers: 12-month prospective follow-up. Eur Spine J 2008, 17:393-405.

12. Laaksonen DE, Lakka HM, Salonen JT, Niskanen LK, Rauramaa R, Lakka TA: Low levels of leisure-time physical activity and cardiorespiratory fitness predict development of the metabolic syndrome. Diabetes Care 2002, 25:1612-1618

13. Holth HS, Werpen HK, Zwart JA, Hagen K: Physical inactivity is associated with chronic musculoskeletal complaints 11 years later: results from the Nord-Trøndelag Health Study. BMC Musculoskelet Disord 2008, 9:159.

14. Mäkelä M, Heliövaara M, Sievers K, Impivaara O, Knekt P, Aromaa A: Prevalence, determinants, and consequences of chronic neck pain in Finland. Am J Epidemiol 1991, 134:1356-1367.

15. Viikari-Juntura E, Martikainen R, Luukkonen R, Mutanen P, Takala E-P, Riihimäki H: Longitudinal study of work-related and individual risk factors of radiating neck pain. Occup Environ Med 2001, 58:345-352.

16. van Raalte DH, Ouwens DM, Diamant M: Novel insights into glucocorticoid-mediated diabetogenic effects: towards expansion of therapeutic options? Ear J Clin Invest 2009, 39:81-93.

17. McBeth J, Silman AJ, Gupta A, Chiu YH, Ray D, Morriss R, Dickens C, King Y, Macfarlane GJ: Moderation of psychosocial risk factors through dysfunction of the hypothalamic-pituitary-adrenal stress axis in the onset of chronic widespread musculoskeletal pain: findings of a population-based prospective cohort study. Arthritis Rheum 2007, 56:360-371.

18. Saltevo J, Vanhala M, Kautiainen H, Kumpusalo E, Laakso M: Gender differences in C-reactive protein, interleukin-1 receptor antagonist and adiponectin levels in the metabolic syndrome: a population-based study. Diabet Med 2008, 25:747-750

19. Leijon O, Wahlström J, Mulder M: Prevalence of self-reported neckshoulder-arm pain and concurrent low back pain or psychological distress: time-trends in a general population, 1990-2006. Spine (Phila Pa 1976) 2009, 34:1863-1868.

20. Grundy SM, Hansen B, Smith SC Jr, Cleeman Jl, Kahn RA, American Heart Association; National Heart, Lung, and Blood Institute; American Diabetes Association: Clinical management of metabolic syndrome: report of the American Heart Association/National Heart, Lung, and Blood Institute/ American Diabetes Association conference on scientific issues related to management. Circulation 2004, 109:551-556.

21. Grundy SM, Cleeman JI, Daniels SR, Donato KA, Eckel RH, Franklin BA, Gordon DJ, Krauss RM, Savage PJ, Smith SC Jr, Spertus JA, Costa F: Diagnosis and management of the metabolic syndrome: an American Heart Association/National Heart, Lung, and Blood Institute Scientific Statement. Circulation 2005, 112:2735-2752.

22. Goldberg DP, Gater R, Sartorius N, Ustun TB, Piccinelli M, Gureje O, Rutter C: The validity of two versions of the GHQ in the WHO study of mental illness in general health care. Psychol Med 1997, 27:191-197.

23. Skillgate $E$, Vingård $E$, Josephson $M$, Holm LW, Alfredsson L: Is smoking and alcohol consumption associated with long-term sick leave due to unspecific back or neck pain among employees in the public sector? Results of a three-year follow-up cohort study. J Rehabil Med 2009, 41:550-556.

24. Goldbacher EM, Matthews KA: Are psychological characteristics related to risk of the metabolic syndrome? A review of the literature. Ann Behav Med 2007, 34:240-252. 
25. Yoo HL, Eisenmann JC, Franke WD: Independent and combined influence of physical activity and perceived stress on the metabolic syndrome in male law enforcement officers. J Occup Environ Med 2009, 51:46-53.

26. McBeth J, Symmons DP, Silman AJ, Allison T, Webb R, Brammah T,

Macfarlane GJ: Musculoskeletal pain is associated with a long-term increased risk of cancer and cardiovascular-related mortality. Rheumatology (Oxford) 2009, 48:74-77.

\section{Pre-publication history}

The pre-publication history for this paper can be accessed here: http://www.biomedcentral.com/1471-2474/11/171/prepub

doi:10.1186/1471-2474-11-171

Cite this article as: Mäntyselkä et al:: Prevalence of neck pain in subjects with metabolic syndrome - a cross-sectional population-based study. BMC Musculoskeletal Disorders 2010 11:171.

\section{Submit your next manuscript to BioMed Central} and take full advantage of:

- Convenient online submission

- Thorough peer review

- No space constraints or color figure charges

- Immediate publication on acceptance

- Inclusion in PubMed, CAS, Scopus and Google Scholar

- Research which is freely available for redistribution

Submit your manuscript at www.biomedcentral.com/submit 